Findings Obtaining a diagnosis was a difficult process characterised by delays, alternative diagnoses, uncertainty and conflict (inter-professional and parent-professional) that related to the condition's rare and newly recognised status. Families experienced an MS diagnosis as both a desirable and undesirable event in their lives. Disclosure of the diagnosis to others produced a range of responses including disbelief which could contribute to an ongoing sense of uncertainty. Life with childhood MS was a challenging and distressing experience for families because of its uncertain and variable nature. Parents and young people reported feelings of depression and isolation. Families lacked information about the condition and found it difficult accessing specialist expertise as well as peer support due to the condition's rarity. Different service models were evident across the UK with adult services playing a key role in supporting families and paediatric clinicians. Healthcare professionals faced challenges in organising services and therapies (including medications) to support families at home and in school. This was compounded by the variable and unpredictable needs of children/young people with MS. Families valued receiving support from a specialist nurse although this was not provided by many centres.

Conclusions This study has illuminated young people's, parents' and professionals' experiences of childhood MS, how services are organised and the current gaps in support. These findings may have relevance to other rare childhood conditions.

\section{G18 EVALUATION OF A PEER PARENTING SUPPORT SCHEME FOR PARENTS OF DISABLED CHILDREN}

${ }^{1,2} \mathrm{~L}$ Bray, ${ }^{2,3} \mathrm{~B}$ Carter, ${ }^{2,3} \mathrm{C}$ Sanders, ${ }^{2} \mathrm{~K}$ Keegan. ${ }^{1}$ Evidence-Based Practice Research Centre, Edge Hill University, Ormskirk, UK; ${ }^{2}$ Children's Nursing Research Unit, Alder Hey Children's NHS Foundation Trust, Liverpool, UK; ${ }^{3}$ School of Health, University of Central Lancashire, Preston, UK

\subsection{6/archdischild-2015-308599.18}

Aim This presentation will discuss findings from a study which evaluated Scope's Face 2 Face peer parenting support scheme for parents of children with a disability or additional need within a regional children's hospital.

Methods Data were collected before and after the period of befriending from the parents providing support (befrienders) and the parents receiving support (befriendees). This was a mixed methods study. Quantitative data were collected from the administration of four structured questionnaires (GHQ-12, Paediatric Inventory for Parents, Peds QL ${ }^{\mathrm{TM}}$ Family Impact Module, Contact with Health Professionals). Qualitative data were collected during semi-structured qualitative interviews.

Results 26 befriendees (24 mothers and 2 fathers) and 13 befrienders participated in the research project. In total 72 sets of questionnaires were completed and 75 interviews were conducted. The parents in this study (befriendees and befrienders) demonstrated high levels of psychological distress (GHQ-12 scores) before befriending compared to other published parent literature. The befriendees and befrienders reported positive experiences of the scheme and this was reflected in their improved questionnaire scores for psychological wellbeing, family functioning and health related quality of life. Despite improved scores the parents continued to demonstrate poor psychological and emotional wellbeing. After the befriending experience, the befriendees reported coping better, developing a positive view of being a parent to a disabled child and feeling more able to move forwards. The befrienders described both a sense of fulfilment and worth at being able to help and support another parent and they expressed a renewed sense of wellbeing.

Conclusion The findings demonstrated the need to address and support the emotional wellbeing of parents with disabled children and highlights the importance of this support being delivered by other parents who 'know and have been there'. Befrienders and befriendees reported improvements in psychological well-being, family functioning and health-related quality of life.

\section{G19 IMPROVING OUT OF HOURS PAEDIATRIC SERVICES: THE ROLE OF A CLINICAL NURSE COORDINATOR AT A TERTIARY CHILDREN'S HOSPITAL}

K Nathan, J Cherrington, S Sandhu, A Hensman, S Wright, J Gilchrist. Acute Assessment Unit, Sheffield Children's Hospital NHS Foundation Trust, Sheffield, UK

\subsection{6/archdischild-2015-308599.19}

Background $75 \%$ of hospital working time is out of hours. The Department of Health recognises that patient safety in hospitals during these hours is a significant problem and recommends this as an area for change 1,2. Hospital at night (HaN) services have been implemented to address this concern. The HaN ethos aims to deliver safe patient care by utilising the skill mix and competences of a centralised multidisciplinary team 3 . Senior paediatric nurses are often more experienced than junior doctors at managing paediatric patients and delivering clinical care and are therefore suited to undertake coordinator roles in such settings. This enables them to undertake work traditionally performed by doctors and also provide support to ward nurses 4,5.

Aim To evaluate the effect of a $\mathrm{HaN}$ clinical nurse coordinator (CNC) on the workload of the medical team.

Method 8 senior nursing staff with advanced skills were recruited to pilot a clinical nursing $\mathrm{HaN}$ role for 6 months, between the hours of 18.00-02.00 daily. The nurses held the medical SHO bleep and were responsible for triaging, undertaking procedures, performing reviews and coordinating escalation of care.

A proforma was developed to gain quantitative evidence of the bleeps received, jobs completed and jobs escalated which was then used as an audit tool to analyse the effectiveness of the role. This was entered into an excel database and analysed monthly.

A qualitative questionnaire was sent to medical and nursing staff to get further feedback on the role.

Results Data was collected for 174 consecutive days during each CNC shift. The total number of jobs received was 3209 . The CNC performed 784/1148 (68\%) of procedures, 347/983 (35\%) reviews, 84/430 (20\%) prescriptions and 144/643 (22\%) other jobs.

$719 / 1060(68 \%)$ of jobs were completed in less than $30 \mathrm{~min}$.

$100 \%$ of doctors reported that they had more time to complete tasks. $76 \%$ of nurses felt it enabled more direct patient care.

Conclusion This pilot evaluation shows that the CNC was able to perform a significant number of medical jobs. The role was valued by both nurses and doctors enabling more time for patient care. Following the success of this pilot scheme a full time $\mathrm{HaN}$ team has been appointed. 